\title{
ABOUT THE ROBUSTNESS OF ADAPTIVE FEEDBACK LINEARIZATION CONTROLLER FOR INPUT PERTURBED UNCERTAIN FULLY-ACTUATED SYSTEMS
}

\author{
Nguyen Van Chi ${ }^{1, *}$, Nguyen Hien Trung ${ }^{1}$, Nguyen Doan Phuoc ${ }^{2}$, \\ ${ }^{I}$ Thai Nguyen University of Technology, 3/2 Street Tich Luong, Thai Nguyen \\ ${ }^{2}$ Hanoi University of Science and Technology, 1 Dai Co Viet Street, Hanoi \\ "Email: ngchi@tnut.edu.vn
}

Received: 21 May 2015; Accepted for publication: 25 November 2015

\begin{abstract}
The paper proposes a theorem to assert the arbitrarily good robustness of the fully actuated mechanical system controlled by the adaptive feedback linearization controller. The fully actuated system to be controlled is considerately perturbed by input disturbances and contains constant uncertain parameters in its Euler-Lagrange forced model. It is shown in this paper that independent of input disturbances of the adaptive feedback linearization controller with appropriately chosen parameters will drive the output of controlled systems to the desired trajectory for any arbitrary precision. The adaptive controller is applied to the two-link planar elbow arm robot with unknown mass of the end-effector of second link and input torque noises caused by the viscous friction forces and Coulomb friction terms. Simulation results show that the arbitrary precision of the tracking errors always is guaranteed.
\end{abstract}

Keywords: feedback linearization, robust adaptive feedback control, uncertain systems, EulerLagrange forced model.

\section{INTRODUCTION}

The uncertainness of fully actuated mechanical systems, which is commonly described by an Euler-Lagrange forced model as follows [1]:

$$
M(\underline{q}, \underline{\theta}) \underline{\ddot{q}}+C(\underline{q}, \underline{\dot{q}}, \underline{\theta}) \underline{\dot{q}}+\underline{g}(\underline{q}, \underline{\theta})=\underline{u}
$$

is understood that the $\underline{q}$ - dimensional vector and $\underline{\theta}$ of model parameters are constant but unknown, which is however linear dependent on the system in the sense of:

$$
M(\underline{q}, \underline{\theta}) \underline{\ddot{q}}+C(\underline{q}, \underline{\dot{q}}, \underline{\theta}) \underline{\dot{q}}+\underline{g}(\underline{q}, \underline{\theta})=F_{0}(\underline{q}, \underline{\dot{q}}, \underline{\ddot{q}})+F(\underline{q}, \underline{\dot{q}}, \underline{\ddot{q}}) \underline{\theta}
$$

In the Euler-Lagrange model given above the $n$ dimensional vector $\underline{q}$ is called the vector of configuration variables, $\underline{u}$ is the $n$ dimensional vector of $n$ control inputs, $M(\underline{q}, \underline{\theta}) \in \mathbb{R}^{n \times n}$ 
is the inertia matrix, which is symmetric and positive definite, and $C(\underline{q}, \underline{\dot{q}}, \underline{\theta}) \in \mathbb{R}^{n \times n}$ is the centripetal and coriolis forces corresponding matrix.

To tracking control for this uncertain system in the sense, that the tracking error $\underline{e}=\underline{q}-\underline{q} r$ has to be bounded for all $t \geq 0$ and asymptotically convergence to the origin, where $\underline{q}_{r}(t)$ is any desired trajectory, the adaptive controller presented in $[1,2]$ :

$$
\left\{\begin{array}{l}
\underline{\dot{\hat{\theta}}}=(B F)^{T} P \underline{x} \text { with } \underline{x}=\operatorname{col}(\underline{e}, \underline{\dot{e}}) \\
\underline{u}=M(\underline{q}, \underline{\hat{\theta}})\left[\underline{\ddot{q}} r+K_{1} \underline{e}+K_{2} \underline{\dot{e}}\right]+C(\underline{q}, \underline{\dot{q}}, \underline{\hat{\theta}}) \underline{\dot{q}}+\underline{g}(\underline{q}, \underline{\hat{\theta}})
\end{array}\right.
$$

is widely admitted to be an effective solution [ $1-3]$, where the $2 n \times n$ matrix $B$ is defined by:

$$
B=\left(\begin{array}{c}
\Theta \\
M^{-1}(\underline{q}, \underline{\hat{\theta}})
\end{array}\right)
$$

in which $\Theta$ is the $n \times n$ zeros matrix, $K_{1}, K_{2}$ are any two selected $n \times n$ matrices such that the $2 n \times 2 n$ matrix:

$$
A=\left(\begin{array}{cc}
\Theta & I \\
-K_{1} & -K_{2}
\end{array}\right)
$$

with the $n \times n$ identity matrix $I$, will be Hurwitz, and the symmetric positive definite $2 n \times 2 n$ matrix $P$ is the solution of the Lyapunov equation:

$$
\frac{1}{2}\left(A^{T} P+P A\right)=-Q
$$

where $Q$ is also an arbitrarily chosen symmetric positive definite $2 n \times 2 n$ matrix. In many references the adaptive controller (3) is referred to as the adaptive feedback linearization controller.

Furthermore, as it is shown in [2 - 4], for the control problem of input perturbed uncertain systems:

$$
M(\underline{q}, \underline{\theta}) \underline{\ddot{q}}+C(\underline{q}, \underline{\dot{q}}, \underline{\theta}) \underline{\dot{q}}+\underline{g}(\underline{q}, \underline{\theta})=\underline{u}+\underline{n}
$$

where $\underline{n}(t)$ is the vector of input noises, which is assumed to be bounded:

$$
\delta=\sup _{t}|\underline{n}(t)|
$$

the $\underline{q}$-feedback adaptive feedback linearization controller (3) given above always drives the tracking error $\underline{x}=\operatorname{col}(\underline{e}, \underline{\dot{e}})$ of the closed loop system depicted in Fig. 1 asymptotically to the neighborhood $\mathcal{O}$ of the origin defined by:

$$
\mathcal{O}=\left\{\underline{x} \in \mathbb{R}^{2 n}|| \underline{x} \mid \leq \frac{\|P B\| \delta}{\lambda_{\min }(Q)}\right\}
$$

where $\lambda_{\min }(\cdot)$ denotes the minimal eigenvalue and $\|\cdot\|$ the norm of a matrix. The neighborhood $\mathcal{O}$ is also referred as the attractor of closed loop systems. The smaller this attractor is, the better tracking performance of the system is. 


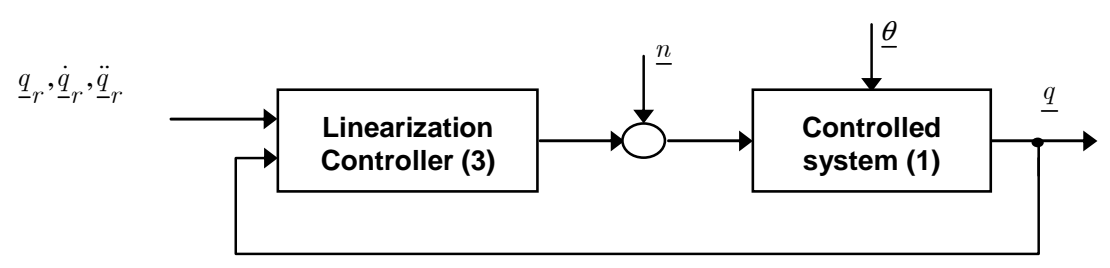

Figurre 1. Structure of the closed loop system obtained by using the adaptive feedback linearization controller (3).

Since the feedback linearization controller (3) contains in it some freely selected parameters such as two matrices $K_{1}, K_{2}$ and the symmetric positive definite matrix $P$, the robust tracking performance defined in the equation (5) above of the closed loop system depicted in 0 could be evidently improved further, if these parameters have been suitably chosen.

And this paper will present a methodology to determine matrices $K_{1}, K_{2}, P$ for adaptive feedback linearization controller (3) so that the tracking behaviour of the obtained closed loop system satisfies any desired arbitrarily small attractor $\mathcal{O}$.

\section{MAIN RESULT}

Also according to the suggestion of [1], both matrices $K_{1}, K_{2}$ of the feedback linearization controller (3) could be chosen diagonally:

$$
K_{1}=\operatorname{diag}\left(k_{1 i}\right), K_{2}=\operatorname{diag}\left(k_{2 i}\right), i=1,2, \ldots, n
$$

and appropriately the matrix $Q$ of the form:

$$
Q=\left(\begin{array}{cc}
K_{1}^{2} & \Theta \\
\Theta & K_{2}^{2}-K_{1}
\end{array}\right)=\left(\begin{array}{cc}
\operatorname{diag}\left(k_{1 i}^{2}\right) & \Theta \\
\Theta & \operatorname{diag}\left(k_{2 i}^{2}-k_{1 i}\right)
\end{array}\right)
$$

In this circumstance the matrix $A$ is Hurwitz if and only if:

$$
k_{1 i}>0, k_{2 i}^{2}>k_{1 i} \text { for all } i=1,2, \ldots, n
$$

and the Lyapunov equation has the following unique solution:

$$
P=\left(\begin{array}{cc}
2 K_{1} K_{2} & K_{1} \\
K_{1} & K_{2}
\end{array}\right)
$$

which is obviously symmetric and positive definite. follows:

Moreover, it is easily to recognize from the equation (5), that the measure of $\mathcal{O}$ defined as

$$
m(\mathcal{O})=\max _{\underline{x}, \underline{y}}|\underline{x}-\underline{y}| \text { for all } \underline{x}, \underline{y} \in \mathcal{O}
$$

is an intuitive value to appreciate the robustness of the closed loop system. The smaller $m(\mathcal{O})$ is, the better robustness of the system is. 
Theorem: For any given $\varepsilon>0$ always exits two matrices $K_{1}, K_{2}$ such that the proposed $\underline{q}$ feedback dynamic controller (3) satisfies the desired robustness:

$$
m(\mathcal{O}) \leq \varepsilon
$$

Proof:

Chosen $K_{1}, K_{2}$ diagonally with:

$$
K_{1}=\operatorname{diag}(k), k>1 \text { and } K_{2}=\operatorname{diag}(a k), a>\sqrt{2}
$$

as well as $Q$ from the structure (6), then there are obtained:

$$
\begin{array}{cc} 
& \|P B\|=\left\|\left(\begin{array}{cc}
2 K_{1} K_{2} & K_{1} \\
K_{1} & K_{2}
\end{array}\right)\left(\begin{array}{c}
\Theta \\
\hat{M}^{-1}
\end{array}\right)\right\|=\left\|\left(\begin{array}{c}
K_{1} \hat{M}^{-1} \\
K_{2} \hat{M}^{-1}
\end{array}\right)\right\| \leq \gamma \max \left(k_{1 i}, k_{2 i}\right) \\
\text { and } & Q=\left(\begin{array}{cc}
K_{1}^{2} & \Theta \\
\Theta & K_{2}^{2}-K_{1}
\end{array}\right)=\left(\begin{array}{cc}
\operatorname{diag}\left(k_{1 i}^{2}\right) & \Theta \\
\Theta & \operatorname{diag}\left(k_{2 i}^{2}-k_{1 i}\right)
\end{array}\right) \\
\Rightarrow \quad \lambda_{\min }(Q)=\min _{i}\left(k_{1 i}^{2}, k_{2 i}^{2}-k_{1 i}\right)
\end{array}
$$

where $\bar{M}$ is the short expression of the matrix $M(\underline{q}, \underline{\hat{\theta}})=\left(m_{i j}(\underline{q}, \underline{\hat{\theta}})\right)$ and:

$$
\gamma=\left\|\bar{M}^{-1}\right\|=\max _{1 \leq i \leq m} \sum_{j=1}^{m}\left|m_{i j}(\underline{q}, \underline{\hat{\theta}})\right|
$$

Hence, it deduces:

$$
\begin{aligned}
\frac{\|P B\| \delta}{\lambda_{\min }(Q)} & =\frac{\gamma \delta \max _{i}(k, a k)}{\min _{i}\left(k^{2}, a^{2} k^{2}-k\right)}=\frac{\gamma \delta a k}{\min _{i}\left(k^{2}, a^{2} k^{2}-k\right)} \\
& \leq \frac{\gamma \delta a k}{\min _{i}\left(k^{2}, a^{2} k^{2}-k^{2}\right)}=\frac{\gamma \delta a k}{\min _{i}\left(k^{2},\left(a^{2}-1\right) k^{2}\right)}=\frac{\gamma \delta a}{k}
\end{aligned}
$$

and from which to find out:

$$
\lim _{k \rightarrow \infty} \frac{\gamma \delta a}{k}=0
$$

Therefore, by any given $\varepsilon>0$ always exists a sufficiently large number $k>0$ such that:

$$
m(\mathcal{O}) \leq \frac{\gamma \delta a}{k}<\varepsilon
$$

which affirms the rightness of Theorem.

\section{NUMERICAL EXAMPLE}

To illustrate the proposed theorem it is considered hereafter a two-link planar elbow arm robot (Fig. 2), which is now additionally perturbed by input noises $\underline{n}=\left(n_{1}, n_{2}\right)^{T}$ and described by the uncertain Euler-Lagrange forced model (4) with the following parameters [1]: 


$$
\begin{aligned}
& \underline{q}=\left(\begin{array}{c}
\varphi_{1} \\
\varphi_{2}
\end{array}\right), \underline{u}=\left(\begin{array}{c}
\tau_{1} \\
\tau_{2}
\end{array}\right), \underline{n}=\left(\begin{array}{l}
n_{1} \\
n_{2}
\end{array}\right) \\
& M(\underline{q}, \underline{\theta})=\left(\begin{array}{cc}
(m+\theta) l_{1}^{2}+\theta l_{2}^{2}+2 \theta l_{1} l_{2} \cos \varphi_{2} & \theta\left(l_{2}^{2}+l_{1} l_{2} \cos \varphi_{2}\right) \\
\theta\left(l_{2}^{2}+l_{1} l_{2} \cos \varphi_{2}\right) & \theta l_{2}^{2}
\end{array}\right) \\
& C(\underline{q}, \underline{\dot{q}}, \underline{\theta})=\left(\begin{array}{cc}
-2 \theta l_{1} l_{2} \dot{\varphi}_{2} \sin \dot{\varphi}_{2} & -\theta l_{1} l_{2} \dot{\varphi}_{2} \sin \dot{\varphi}_{2} \\
\theta l_{1} l_{2} \dot{\varphi}_{1} \sin \varphi_{2} & 0
\end{array}\right) \\
& \underline{g}(\underline{q}, \underline{\theta})=\left(\begin{array}{c}
(m+\theta) g l_{1} \cos \varphi_{1}+\theta g l_{2} \cos \left(\varphi_{1}+\varphi_{2}\right) \\
\theta g l_{2} \cos \left(\varphi_{1}+\varphi_{2}\right)
\end{array}\right)
\end{aligned}
$$

where $\underline{\tau}=\left(\tau_{1}, \tau_{2}\right)^{T}$ is the input vector, in which the torque $\tau_{1}$ produces the angular motion $\varphi_{1}$ and the torque $\tau_{2}$ produces the angular motion $\varphi_{1}$ of robot arms.
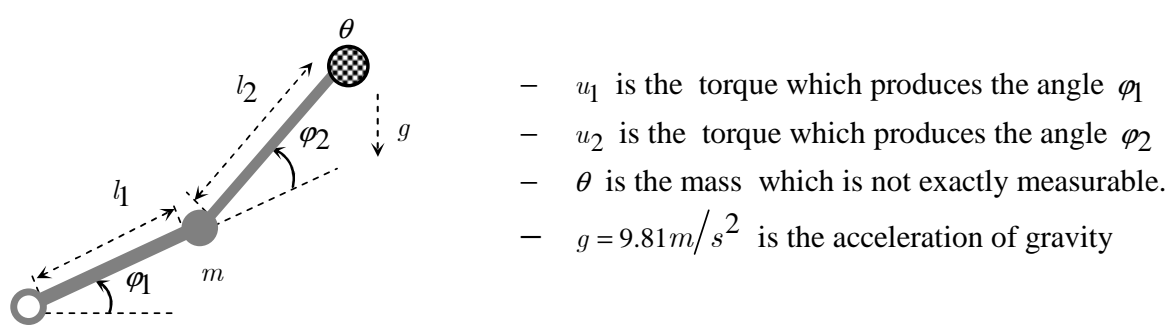

Figure 2. The controlled system is a two-link planar elbow arm robot.

Now, the adaptive controller (3) is applied to the arm robot in Fig. 2 for tracking problem of the angles and the velovities of two links, by using two diagonal matrices $K_{1}, K_{2}$ suggested in (9) with $a=2$ :

$$
K_{1}=\left(\begin{array}{ll}
k & 0 \\
0 & k
\end{array}\right), K_{2}=\left(\begin{array}{cc}
2 k & 0 \\
0 & 2 k
\end{array}\right) \Rightarrow K_{1} K_{2}=\left(\begin{array}{cc}
2 k^{2} & 0 \\
0 & 2 k^{2}
\end{array}\right)
$$

and

$$
P=\left(\begin{array}{cc}
2 K_{1} K_{2} & K_{1} \\
K_{1} & K_{2}
\end{array}\right)=\left(\begin{array}{cccc}
4 k^{2} & 0 & k & 0 \\
0 & 4 k^{2} & 0 & k \\
k & 0 & 2 k & 0 \\
0 & k & 0 & 2 k
\end{array}\right)
$$

the feedback linearization controller (3) for the controlled system (10) with parameters:

$$
g=9.8 \mathrm{~m} / \mathrm{s}^{2}, m=1 \mathrm{~kg}, \theta=2.5 \mathrm{~kg}, l_{1}=0.5 \mathrm{~m}, l_{2}=0.5 \mathrm{~m}
$$

becomes

$$
\dot{\hat{\theta}}=\frac{1}{(c+\hat{\theta} b) l_{2}^{2}}\left(0,0, l_{2}^{2} f_{1}-a f_{2},-a f_{1}+(c / \hat{\theta}+b) f_{2}\right) P\left(\begin{array}{l}
\underline{e} \\
\underline{\dot{e}}
\end{array}\right)
$$

where $\underline{e}=\underline{q}-\underline{q}, \underline{q}=\left(\varphi_{1}, \varphi_{2}\right)^{T}, \underline{q}_{r}=\left(\varphi_{1}^{r}, \varphi_{2}^{r}\right)^{T}$ denotes the tracking deviation and 


$$
\underline{u}=\left(\begin{array}{cc}
c+\hat{\theta} b & \hat{\theta} a \\
\hat{\theta} a & \hat{\theta} l_{2}^{2}
\end{array}\right)\left[\ddot{q}_{r}+k \underline{e}+2 k \underline{\dot{e}}\right]+\left(\begin{array}{c}
-2 d \dot{\varphi}_{1}-d \dot{\varphi}_{2}+(m+\underline{\hat{\theta}}) h+\underline{\hat{\theta}} f \\
e \dot{\varphi}_{1}+\underline{\hat{\theta}} f
\end{array}\right)
$$

with

$$
\begin{array}{ll}
a=l_{2}^{2}+l_{1} l_{2} \cos \varphi_{2}, & d=l_{1} l_{2} \dot{\varphi}_{2} \sin \dot{\varphi}_{2}, f=g l_{2} \cos \left(\varphi_{1}+\varphi_{2}\right) \\
b=l_{1}^{2}+a & e=l_{1} l_{2} \dot{\varphi}_{1} \sin \varphi_{2} \quad h=g l_{1} \cos \varphi_{1} \\
c=m l_{1}^{2} &
\end{array}
$$

and

$$
\begin{gathered}
f_{1}=b \ddot{\varphi}_{1}+a \ddot{\varphi}_{2}-2 d \dot{\varphi}_{1}-d \dot{\varphi}_{2}+h+f \\
f_{2}=a \ddot{\varphi}_{1}+l_{2}^{2} \ddot{\varphi}_{2}+e \dot{\varphi}_{1}+\varphi
\end{gathered}
$$

Figure 3 and Fig. 4 depict angle and velocity simulation results obtained with $k=3, k=10$ and $k=30$ respectively. In this simulation, the input noises applying in two links are considered to be depend on velocities of the links as below:

$$
\begin{aligned}
& n_{1}(t)=3\left|\dot{\varphi}_{1}\right| \dot{\varphi}_{1} \operatorname{sign}\left(\dot{\varphi}_{1}\right)+0.5 \dot{\varphi}_{2} \operatorname{sign}\left(\dot{\varphi}_{2}\right)+5 \operatorname{rand}(1,1) \\
& n_{2}(t)=5\left|\dot{\varphi}_{2}\right| \dot{\varphi}_{2} \operatorname{sign}\left(\dot{\varphi}_{2}\right)+0.32 \dot{\varphi}_{1} \operatorname{sign}\left(\dot{\varphi}_{1}\right)+5 \operatorname{rand}(1,1)
\end{aligned}
$$

The Fig. 4 shows that the response angles of the robot arm track to the set points after the transient period in 7.5 seconds. There is $0.113 \mathrm{rad}$ of maximum angle errors which reduce to $2.55 \times 10^{-3}$ rad by using $k=10$ and $5.3 \times 10^{-4}$ rad by $k=30$ as showing in the Fig. 5. The more $k$ increases, the more angle errors and velocity errors reduce.
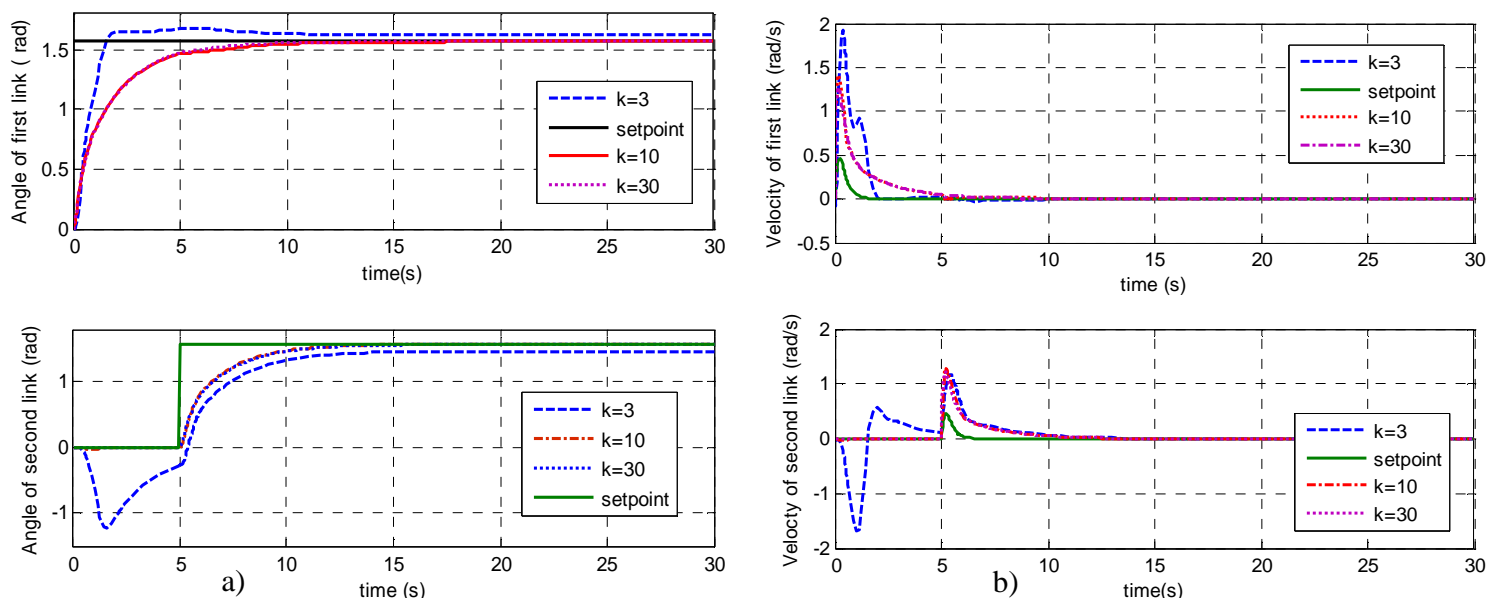

Figure 3. Desired angles, simulated angles (a) and desired velocities, simulated velocities (b) of first link and second link with $k=3, k=10$ and $k=30$. 

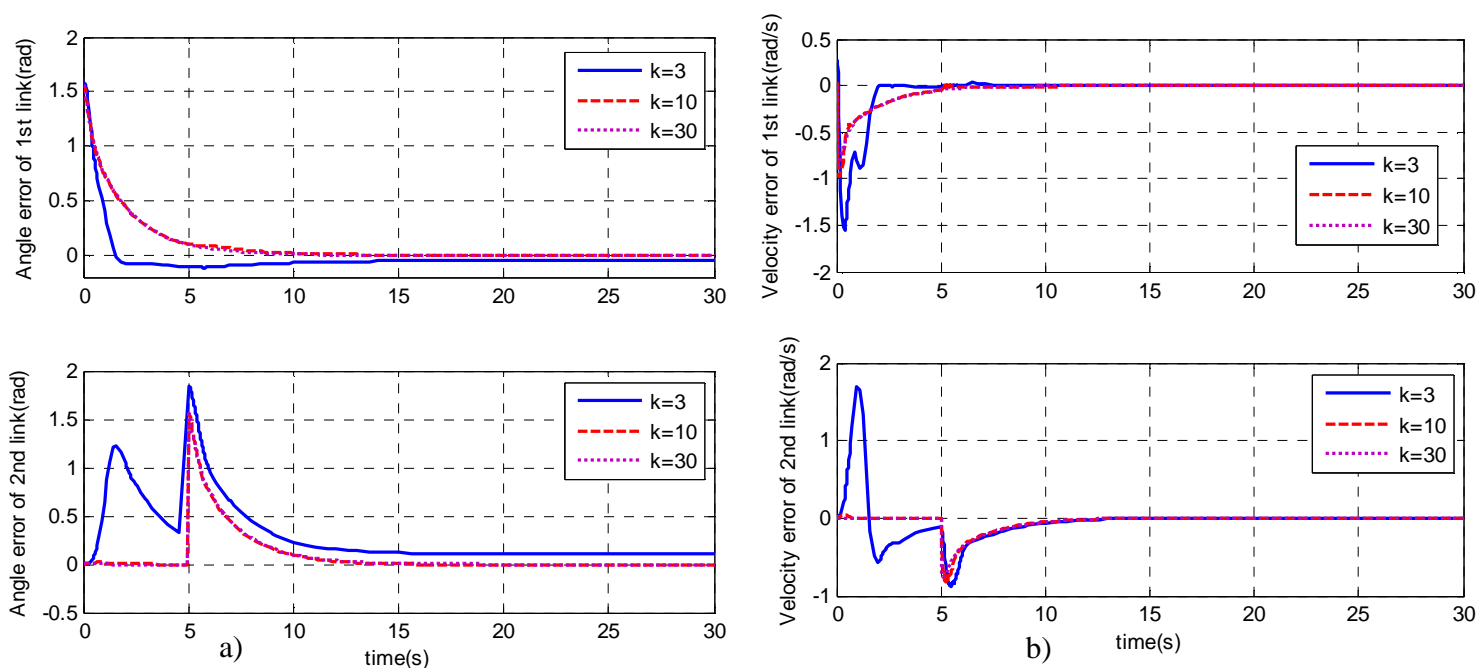

Figure 4. Angle errors(a) and velocities errors (b) of first link and second link with $k=3, k=10$ and $k=30$.
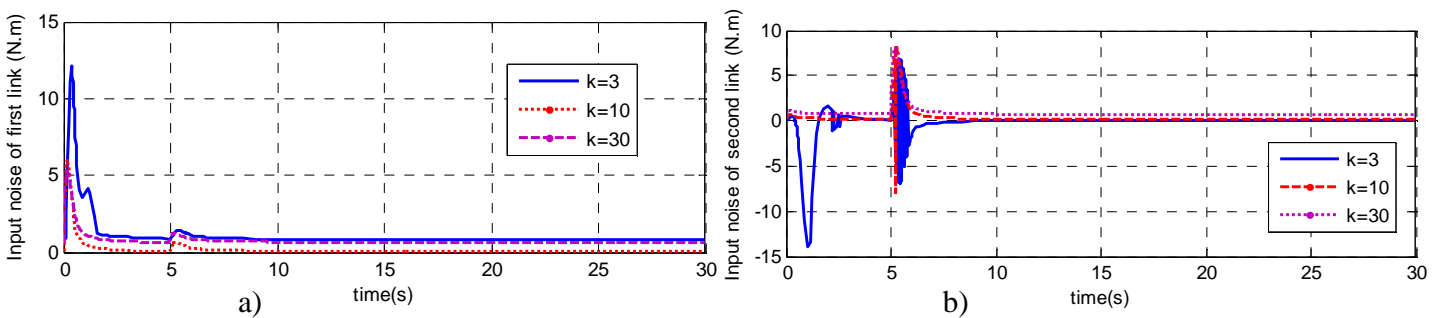

Figure 5. Input noise of the first link (a) and Input noise of the second link (b) with $k=3, k=10$ and $k=30$.
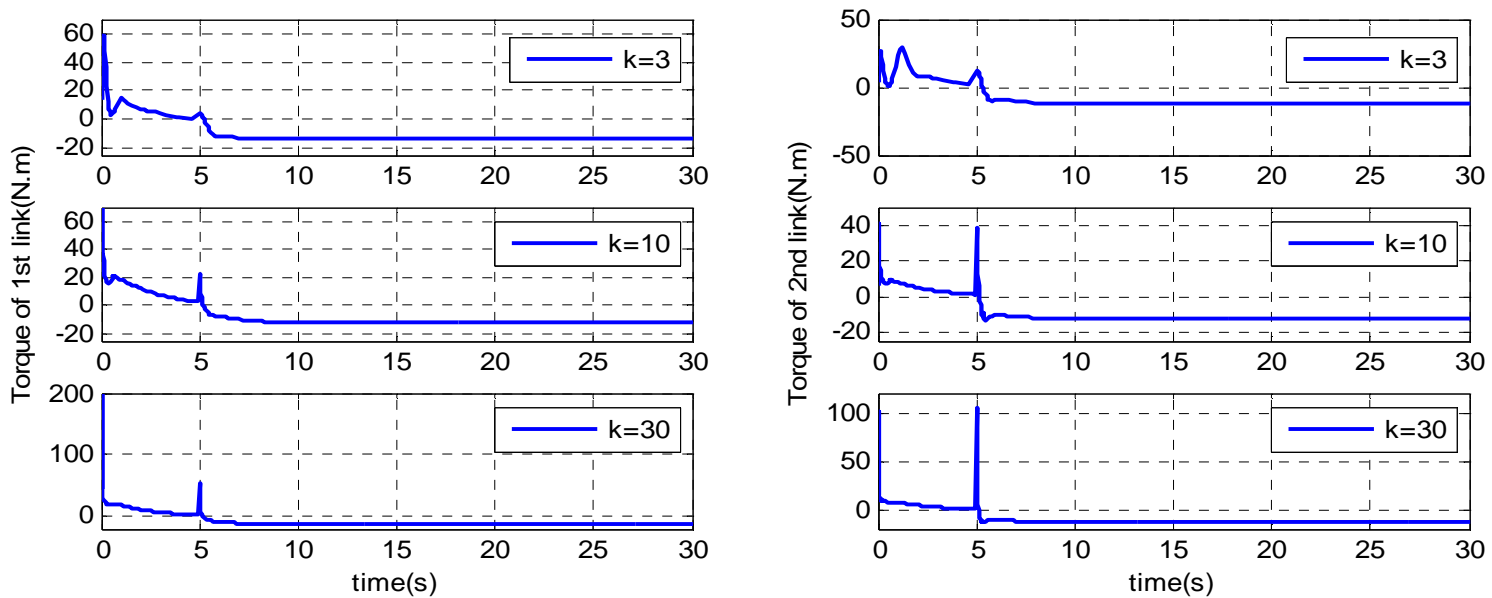

Figure 6. The torques apply to the first link and second link with $k=3, k=10$ and $k=30$.

In the Fig. 6 there are input torques computed by the adaptive controller to get the tracking of the links, the maximum amplitudes of input torques is 60 N.m with $k=3$ and 200 N.m with $k=30$. 


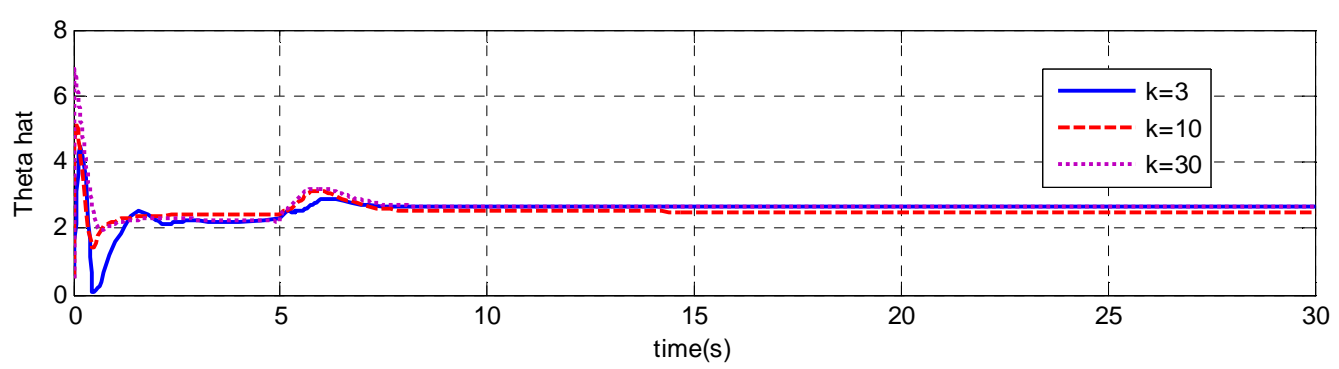

Figure 7. The adaptive parameter $\hat{\theta}$ with $k=3, k=10$ and $k=30$.
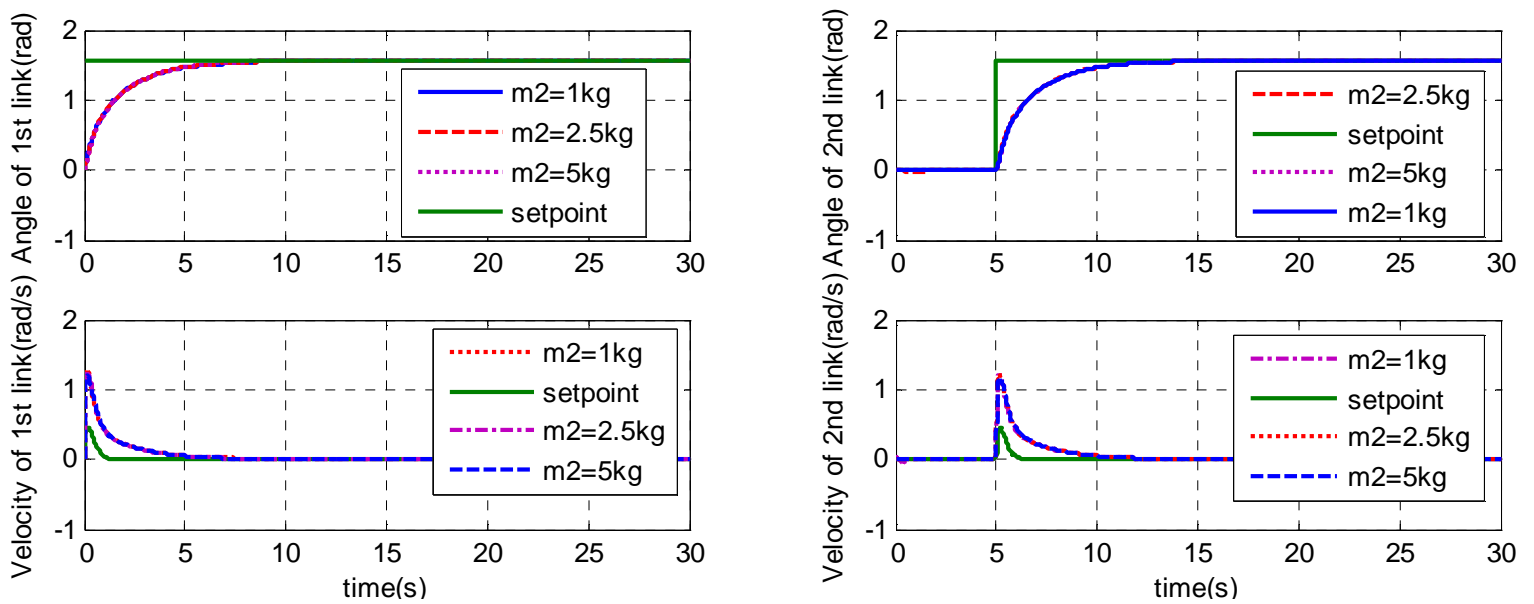

Figure 8. The responses of angle and velocity with changing of the mass of the end-effector.

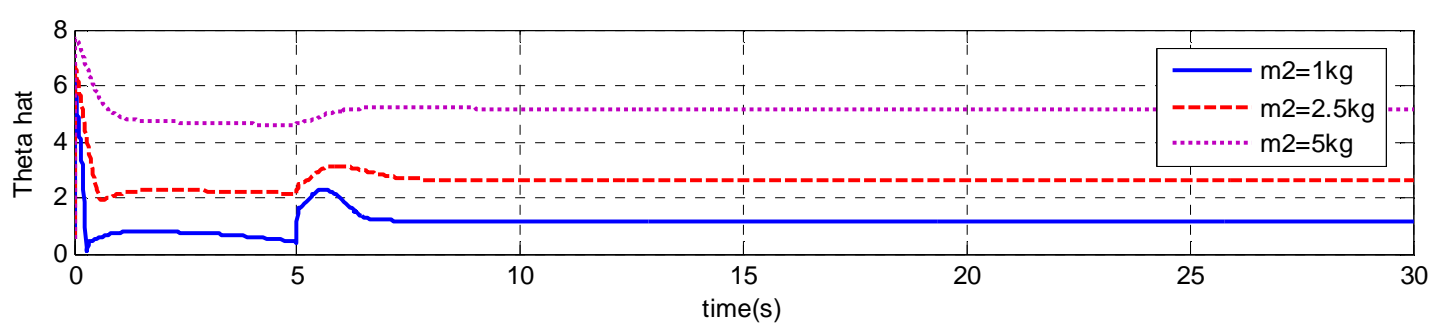

Figure 9. The adaptive parameter $\hat{\theta}$ with changing of the mass of the end-effector.

The adaption of the parameter $\hat{\theta}$ with $k=3, k=10$ and $k=30$ are depicted in the Fig. 7 . It changes strongly when the arm robot is effected by input noises and it reached to the real value of the mass of the end-effector when the input noises are zero. The Fig. 8 shows that the angle and velocity responses by changing of the mass at the end-effector with $m_{2}=1 \mathrm{~kg}$, $m_{2}=2.5 \mathrm{~kg}$ and $m_{2}=5 \mathrm{~kg}$ are not quite different. It means that the influence of $m_{2}$ to the angles and velocities has been attenuated by the adaptation of $\hat{\theta}$ as showing in Fig. 9. Finally, all obtained simulation results above have concluded that any desired robustness for the control of systems with unknown parameters and input noises (4), will be always satisfied with the feedback linearization controller (3). 


\title{
3. CONCLUSIONS
}

This paper refers to robustness of the fully actuated mechanical system which is considered by Euler - Lagrange forced model with input disturbances and contains constant uncertain parameters. By giving and proofing a theorem we conclude that the outputs of the system controlled by the adaptive feedback linearization controller will track to the desired trajectories for any arbitrary precision with appropriately chosen controller parameters. The adaptive controller is proposed in this paper not only keeps the tracking of the outputs in the presence of the uncertain parameters but also attenuates the influence of the input noises to the system. For more details, the adaptive controller is applied to the tracking problem of the two-link planar elbow arm robot with unknown mass of the end-effector and the influences of the noises to the input torques, the simulation results show that we can get the arbitrary precision of the angles and velocities of the links. The proof of the convergence of adaptive parameters to real values of unknown parameters and applying this control method to the practice are our further researches.

\section{REFERENCES}

1. Levis F.L; Dawson D.M. and Abdalla C.T. - Robot manipulator control. Theory and practice, Marcel Decker Inc, (2006).

2. Chi N.V and Phuoc N.D. - Adaptive tracking control based on disturbance attenuation and ISS stabilization of Euler-Lagrange nonlinear in the presence of uncertainty and input noise, Proceedings of IEEE 2th Int. Conference on Electrical Engineering and Automation Control (EEAC2011), Aug. 2011 China, pp. 3698-3071, (2011)

3. Quan N.T. and Phuoc N.D. - Robust and adaptive control of Euler-Lagrange systems with an attractor independent of uncertainties, Proceedings of IEEE 12th Int, Conference on Control, Automation and Systems ICCAS 2012, IEEE Catalog Number CFP1210D-CDR, (2012) pp. 1309-1312.

4. Chi Nguyen Van, Phuoc Nguyen Doan -Adaptive ISS Stabilization Tracking Control Of Nonlinear Systems In The Presence Of Uncertainty And Input Noise With Guaranteed Tracking Errors, Journal of Computer Science and Cybernetics 29 (2) (2013) 132-141.

\section{TÓM TẮT}

\section{NGHIÊN CÚU TÍNH BỀN VƯNG CỦA BỘ ĐIỀU KHIỂN TUYẾN TÍNH HÓA PHẢN HỒI THIÍCH NGHI CHO CÁC HỆ CƠ KHÍ ĐẦY ĐỦ CƠ CẤU CHẤP HÂNH CÓ NHIỄU BÂT ĐỊNH ẢNH HƯỞNG ĐẾN ĐẦU VÀO}

\author{
Nguyễn Văn Chî ${ }^{1}$, Nguyễn Hiền Trung ${ }^{1}$, Nguyễn Doãn Phước ${ }^{2}$ \\ ${ }^{I}$ Đại học Kỹ thuật công nghiệp Thái Nguyên, Đường 3/2 - Tích Luơng, TP Thái Nguyên \\ ${ }^{2}$ Đại học Bách khoa Hà Nội, Số 1 Đại Cồ Việt, Hà Nội \\ "Email:ngchi@tnut.edu.vn
}

Bài báo này đưa ra một định lí và khẳng định tính bền vững tùy ý cho hệ cơ khí đầy đủ cơ cấu chấp hành có các tham số bất định và nhiễu đầu vào mô tả dưới dạng mô hình EulerLagrange được điều khiển bằng bộ điều khiển tuyến tính hóa phản hồi thích nghi. Bộ điều khiển 
tuyến tính hóa phản hồi thích nghi với các tham số được chọn một cách phù hợp sẽ điều khiển đầu ra của hệ bám theo quỹ đạo mong muốn với độ chính xác yêu cầu mà không phụ thuộc vào nhiễu đầu vào. Bộ điều khiển được áp dụng cho hệ robot khuỷu tay hai thanh nối với khối lượng điểm cuối không biết trước và có mô men đầu vào chịu ảnh hưởng của các lực ma sát nhớt và các thành phần ma sát Coulomb. Kết quả mô phỏng cho thấy rằng độ chính xác tùy ý của sai lệch bám quỹ đạo luôn luôn được đảm bảo.

Tù khóa: tuyến tính hóa phản hồi, điều khiển phản hồi thích nghi bề vững, các hệ bất định, hệ phi tuyến Euler-Lagrange. 